\title{
QUALIDADE DA ÁGUA DO RIO SANTA MARIA DO DOCE - ES PARA FINS DE IRRIGAÇÃO
}

Caroline Merlo Meneghelli ${ }^{1}$; Paola Alfonsa Vieira Lo Monaco ${ }^{2}$; Jorge Montoanelli Correa $^{3}$; Renan Birchler ${ }^{4}$; Jéssica Broseghini Loss ${ }^{5}$

${ }^{1}$ Engenheira Agrônoma, Mestranda em Produção Vegetal pela Universidade Federal do Espírito Santo. Alegre, Brasil. E-mail: carol.merlo@hotmail.com

${ }^{2}$ Engenheira Agrícola, Professora do Instituto Federal de Educação, Ciência e Tecnologia do Espírito Santo- IFES, campus Santa Teresa. Santa Teresa, Brasil.

${ }^{3}$ Engenheiro Agrônomo, Mestrando em Produção Vegetal pela Universidade Federal do Espírito Santo. Alegre, Brasil

${ }^{4}$ Estudante de Agronomia do Instituto Federal de Educação, Ciência e Tecnologia do Espírito Santo IFES, campus Santa Teresa. Santa Teresa, Brasil.

${ }^{5}$ Engenheira Agrônoma, Mestranda em Produção Vegetal pela Universidade Federal do Espírito Santo. Santa Teresa, Brasil.

Recebido em: 03/10/2016 - Aprovado em: 21/11/2016 - Publicado em: 05/12/2016 DOI: 10.18677/EnciBio_2016B_083

\section{RESUMO}

A água utilizada na irrigação deve ser de qualidade para que não haja riscos de entupimento em emissores. Objetivou-se, com a realização deste trabalho, avaliar a qualidade da água da sub-bacia do Rio Santa Maria do Doce, ES, para fins de irrigação em áreas adjacentes. As coletas foram realizadas no mês de Abril do ano de 2016, ao longo do Rio Santa Maria do Doce. Foram selecionados dez pontos, desde a nascente até a foz, coletando-se 1 Litro de amostra em cada ponto. Os atributos de qualidade de água analisados foram Condutividade Elétrica (CE), $\mathrm{pH}$, sólidos dissolvidos totais e sólidos suspensos. Em dois pontos amostrados ao longo do Rio Santa Maria do Doce, o pH está abaixo da faixa estabelecida pela resolução CONAMA 357/2005. Em nenhum dos pontos amostrados, o valor de sólidos dissolvidos totais foi ultrapassado, de acordo com o limite da referida resolução. Em todos os pontos avaliados ao longo do Rio Santa Maria do Doce, o uso da água para irrigação não apresenta riscos de entupimento, no que se refere aos parâmetros de condutividade elétrica, $\mathrm{pH}$, sólidos suspensos e sólidos dissolvidos.

PALAVRAS-CHAVE: Parâmetros qualitativos. Rio Santa Maria do Doce. Sistemas de irrigação.

\section{SANTA MARIA DO DOCE'S RIVER WATER QUALITY FOR IRRIGATION PURPOSES}

\section{ABSTRACT}

The water used in irrigation must be in good quality so there is no clogging risks in issuers. The objective of this work was to evaluate the water quality of the sub-basin of the river Santa Maria do Doce, ES, for irrigation purposes in adjacent areas. Samples were collected in April 2016, along the Santa Maria do Doce river. Ten spots were selected from the source till the mouth, and it was collected 1 liter sample ENCICLOPÉDIA BIOSFERA, Centro Científico Conhecer - Goiânia, v.13 n.2879. 
at each spot. The water quality attributes analyzed were: Electrical Conductivity (EC), $\mathrm{pH}$, dissolved solids and suspended solids. The $\mathrm{pH}$ measured in two sampled spots along the river Santa Maria do Doce was below the established range by resolution CONAMA 357/2005. The total value of dissolved solids in all the sampled spots didn't exceed according to the limit of the resolution. In all spots assessed throughout the river Santa Maria do Doce, the use of water for irrigation hasn't any clogging risks, in regard to the parameters of electrical conductivity, $\mathrm{pH}$, dissolved solids and suspended solids.

KEYWORDS: Qualitative parameters. River Santa Maria do Doce. Irrigation systems.

\section{INTRODUÇÃO}

Nos últimos anos, o Rio Santa Maria do Doce, afluente do Rio Doce, vem sendo modificado por diversas ações antropogênicas, resultando em prejuízo na qualidade e disponibilidade de água. No caso da qualidade, tal fato pode ser atribuído ao lançamento de efluentes domésticos e agroindustriais sem tratamento e ao carreamento de partículas orgânicas e inorgânicas, oriundas do escoamento superficial, até o leito do rio. Em relação à disponibilidade, o manejo inadequado do solo em toda a área de contribuição da sub-bacia tem dificultado a infiltração da água no solo e a recarga dos aquíferos, causando um decréscimo na vazão das nascentes. Além disso, tal fato agravou-se pela ocorrência de chuvas abaixo da média histórica nos últimos três anos.

A principal atividade econômica da bacia do Rio Santa Maria do Doce é a agricultura, com amplo uso da irrigação. Em razão de muitas propriedades agrícolas adotarem sistemas de irrigação localizada em suas lavouras, uma atenção especial deve ser dada à qualidade da água, sob risco de causar problemas de entupimento e redução na uniformidade de distribuição de água.

Nos sistemas de irrigação localizada, os emissores apresentam alta suscetibilidade ao entupimento. De acordo com SILVA et al. (2012), a sensibilidade ao problema de entupimento varia com as características do gotejador e com a qualidade da água relacionada aos aspectos físicos, químicos e biológicos. LIU \& HUANG (2009) reforçam que o entupimento de gotejadores prejudica o funcionamento geral do sistema de irrigação afetando suas características de operação e exigindo manutenções mais freqüentes. Comumente, a obstrução diminui a uniformidade de aplicação da água de sistemas de irrigação localizada.

Outro problema relacionado à qualidade da água para irrigação refere-se ao sistema solo-planta. A prática da irrigação com águas de qualidade inferior podem acarretar a incorporação de sais ao perfil do solo, por conter sais solúveis na água. O uso continuado de águas salinas em irrigações, na ausência de lixiviação, provoca a deposição do sal na zona do sistema radicular e na superfície do solo, decorrente da evaporação da água (CARVALHO et al., 2012), prejudicando a permeabilidade do solo e seu manejo (SÁ et al., 2015). O excesso de sais compromete as funções fisiológicas e bioquímicas das plantas, causando estresse osmótico, resultando em distúrbios das relações hídricas, alterações na absorção e utilização de nutrientes essenciais, além do acúmulo de íons tóxicos as plantas (CALVET et al., 2013).

Informações sobre a qualidade da água do manancial são importantes para orientar quanto à necessidade de tratamento para fins de irrigação e seleção de culturas mais tolerantes à salinidade e/ou elementos potencialmente tóxicos. Assim, objetivou-se, com a realização deste trabalho, avaliar a qualidade da água ao longo do Rio Santa Maria do Doce, ES, para fins de irrigação. 


\section{MATERIAL E MÉTODOS}

O estudo foi realizado na Sub-bacia do Rio Santa Maria do Doce, pertencente à Bacia Hidrográfica do Rio Doce. O Rio Santa Maria do Doce desenvolve-se por cerca de $93 \mathrm{~km}$, desde sua nascente na Serra do Gelo, no município de Santa Teresa a $1000 \mathrm{~m}$ de altitude, atravessa o município de São Roque do Canaã e segue até desembocar no rio Doce, junto à sede municipal de Colatina, a $40 \mathrm{~m}$ de altitude. Seus principais afluentes são os rios Santa Júlia, Taboca, Perdido e Vinte e Cinco de Julho (ECOPLAN, 2010).

O clima da região, segundo a classificação de Köppen, enquadra-se no tipo Cwa (subtropical de inverno seco), com temperatura média em torno dos $18{ }^{\circ} \mathrm{C}$ (FERREIRA, et al. 2013). De maneira geral, a topografia possui relevo bastante acidentado, intercalado com reduzidas áreas planas. As coletas foram realizadas no mês de abril do ano de 2016, ao longo do Rio Santa Maria do Doce, onde foram selecionados dez pontos, desde a nascente até a foz, os quais estão descritos na Tabela 1.

Os pontos de coleta foram escolhidos intencionalmente, de modo a permitir a observação da qualidade da água em locais com existência de aglomerados de conjuntos motobombas utilizados para irrigação de lavouras e a acessibilidade da amostragem.

TABELA 1- Localização dos pontos de amostragem de água para análise da qualidade.

\begin{tabular}{|c|c|c|c|c|}
\hline Ponto & Localização & Latitude & Longitude & Altitude (m) \\
\hline 1 & $\begin{array}{c}\text { Nascente } \\
\text { Distrito de Caldeirão }\end{array}$ & $19^{\circ} 59^{\prime} 18^{\prime \prime}$ & $40^{\circ} 46^{\prime} 35^{\prime \prime}$ & $\begin{array}{c}800 \\
688\end{array}$ \\
\hline 2 & $\begin{array}{l}\text { pertencente à cidade de } \\
\text { Santa Teresa- ES }\end{array}$ & $19^{\circ} 57^{\prime} 05^{\prime \prime}$ & $40^{\circ} 44^{\prime} 17^{\prime \prime}$ & \\
\hline 3 & $\begin{array}{l}\text { Distrito de Caldeirão } \\
\text { pertencente à cidade de } \\
\text { Santa Teresa- ES }\end{array}$ & $19^{\circ} 55^{\prime} 19^{\prime \prime}$ & $40^{\circ} 44^{\prime} 35^{\prime \prime}$ & 500 \\
\hline 4 & $\begin{array}{l}\text { Distrito de Várzea Alegre } \\
\text { pertencente à cidade de } \\
\text { Santa Teresa- ES }\end{array}$ & $19^{\circ} 53^{\prime} 35^{\prime \prime}$ & $40^{\circ} 45^{\prime} 09^{\prime \prime}$ & 237 \\
\hline 5 & $\begin{array}{l}\text { Localidade de São } \\
\text { Sebastião pertencente à } \\
\text { cidade de Santa Teresa- ES }\end{array}$ & $19^{\circ} 51^{\prime} 58^{\prime \prime}$ & $40^{\circ} 48^{\prime} 05^{\prime \prime}$ & 162 \\
\hline 6 & $\begin{array}{l}\text { Distrito de Santo Antônio do } \\
\text { Canaã pertencente à cidade } \\
\text { de Santa Teresa- ES }\end{array}$ & $19^{\circ} 50^{\prime} 89^{\prime \prime}$ & $40^{\circ} 41^{\prime} 27^{\prime \prime}$ & 147 \\
\hline 7 & $\begin{array}{l}\text { Distrito de são João de } \\
\text { Petrópolis pertencente à } \\
\text { cidade de Santa Teresa- ES }\end{array}$ & $19^{\circ} 48^{\prime} 79^{\prime \prime}$ & $40^{\circ} 40^{\prime} 34^{\prime \prime}$ & 132 \\
\hline 8 & $\begin{array}{l}\text { Localidade de Vila Verde } \\
\text { pertencente à cidade de São } \\
\text { Roque do Canaã-ES }\end{array}$ & $19^{\circ} 44^{\prime} 94^{\prime \prime}$ & $40^{\circ} 39^{\prime} 29^{\prime \prime}$ & 105 \\
\hline 9 & $\begin{array}{l}\text { Localidade de São Pedro } \\
\text { pertencente à cidade de São } \\
\text { Roque do Canaã-ES }\end{array}$ & $19^{\circ} 42^{\prime} 39^{\prime \prime}$ & $40^{\circ} 39^{\prime} 47^{\prime \prime}$ & 86 \\
\hline 10 & $\begin{array}{l}\text { Distrito de Boapaba } \\
\text { pertencente à cidade de } \\
\text { Colatina-ES (foz) }\end{array}$ & $19^{\circ} 36^{\prime} 15^{\prime \prime}$ & $40^{\circ} 37^{\prime} 12^{\prime \prime}$ & 40 \\
\hline
\end{tabular}

Na Figura 1 apresenta-se uma imagem da Bacia hidrográfica do Rio Santa Maria do Doce. 


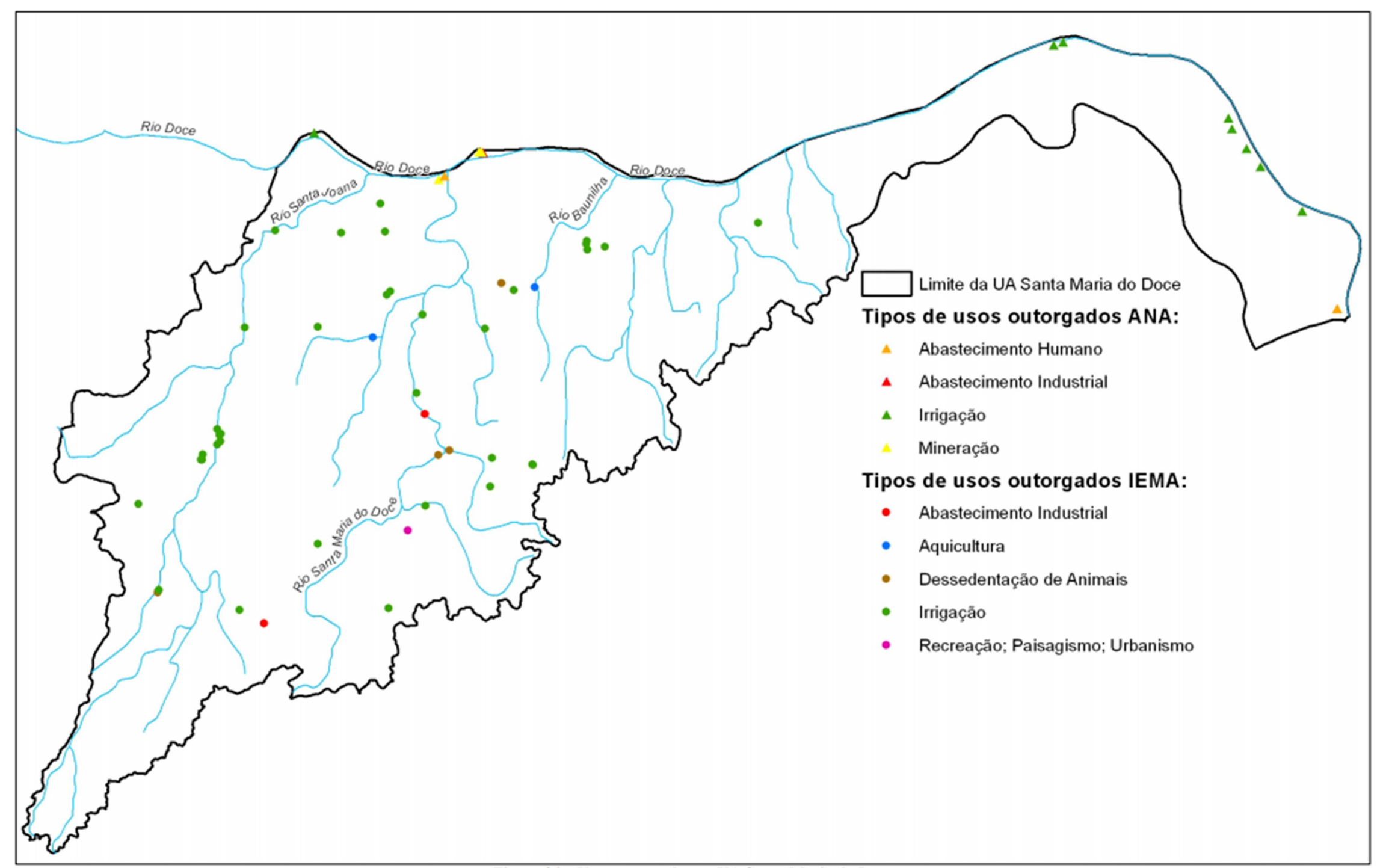

FIGURA 1- Bacia hidrográfica do rio Santa Maria do Doce. Fonte: Ecoplan (2010).

ENCICLOPÉDIA BIOSFERA, Centro Científico Conhecer - Goiânia, v.13 n.24; p. 8822016 
As amostras de água foram coletadas em frascos plásticos com volume de 1 $\mathrm{L}$, os quais foram previamente lavados com água destilada e secados. Antes da coleta propriamente dita, fez-se a tríplice lavagem dos recipientes com a água da fonte de coleta. No ato da coleta, cada amostra recebeu um número de identificação e, posteriormente, foram armazenadas de acordo com a NBR 9898 e encaminhadas aos laboratórios para análise. Os atributos químicos e físicos da qualidade de água analisados foram $\mathrm{pH}$, condutividade elétrica (CE), sólidos dissolvidos totais (SDT) e sólidos suspensos totais (SS). As determinações do $\mathrm{pH}$ e da CE foram realizadas por meio de um peagâmetro e de um condutivímetro de bancada, respectivamente. Os sólidos suspensos totais foram quantificados utilizando o método gravimétrico e os sólidos dissolvidos totais foram determinados por meio do condutivímetro. Todas as análises foram efetuadas seguindo-se a metodologia descrita por Matos (2012) e foram realizadas no Laboratório de Qualidade de Água e Resíduos Sólidos do IFES campus Santa Teresa.

Os resultados foram avaliados realizando-se a estatística descritiva, de forma que os parâmetros analisados foram confrontados com os limites estabelecidos pela Resolução CONAMA 357/2005 (BRASIL, 2005), e de acordo com NAKAYAMA \& BUCKS (1986) e AYERS \& WESTCOT (1999). Os resultados foram dispostos em gráficos contendo os referidos atributos em função dos pontos amostrados ao longo do rio.

\section{RESULTADOS E DISCUSSÃO}

Nas Figuras 2(a), 2(b), 2(c) e 2(d) apresentam-se os valores da condutividade elétrica (CE), do $\mathrm{pH}$, dos sólidos suspensos (SS) e dissolvidos totais (SD) nos diversos pontos amostrados ao longo do Rio Santa Maria do Doce.

(a)

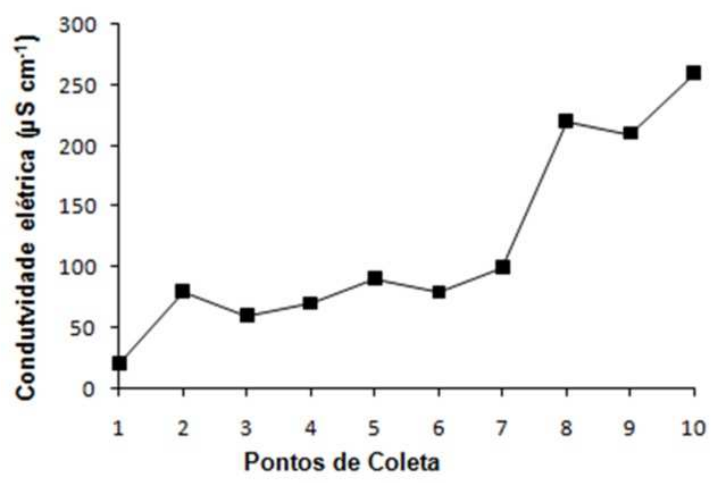

(c)

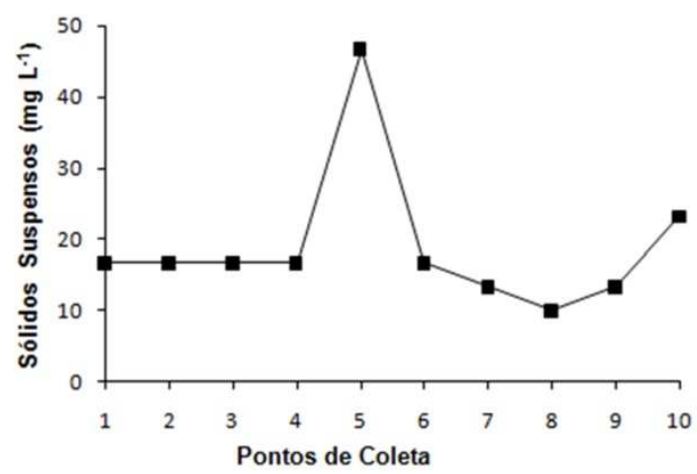

(b)

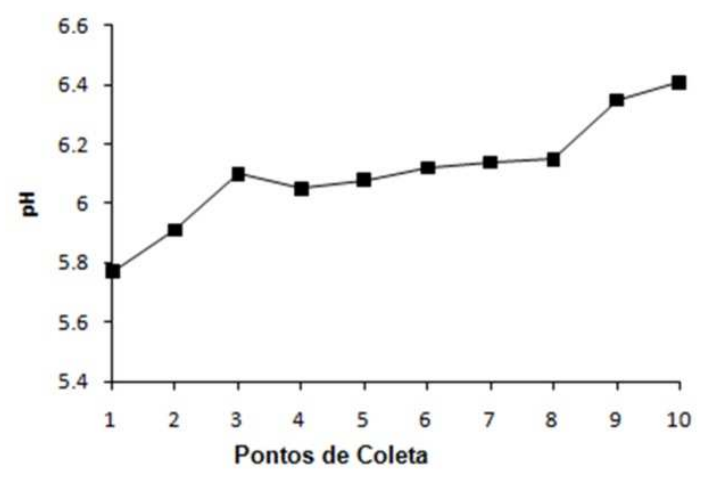

(d)

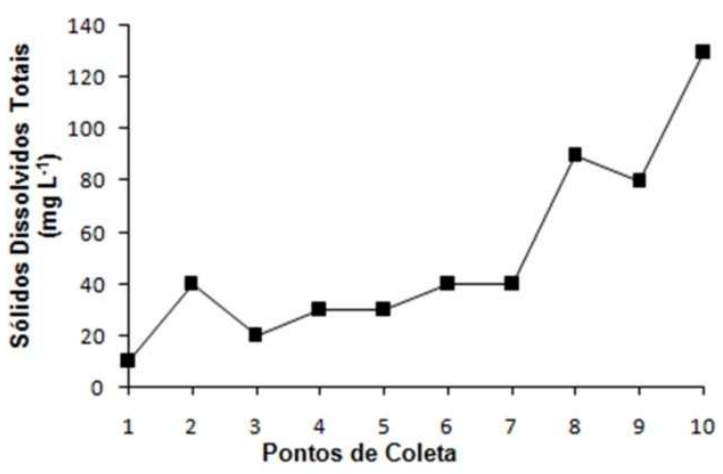

FIGURA 2- Condutividade elétrica (a), pH (b), sólidos suspensos (c) e dissolvidos (d) nos diversos pontos amostrados ao longo do Rio Santa Maria do Doce. 
A condutividade elétrica da água é o parâmetro mais empregado para avaliar a salinidade da água, a qual corresponde à medida da capacidade dos íons presentes na água em conduzir eletricidade e cresce proporcionalmente ao aumento da concentração dos sais (RIBEIRO et al., 2005). De acordo com a Figura 2(a), os valores de condutividade variaram de 20 a $260 \mu \mathrm{S} \mathrm{cm}{ }^{-1}$, apresentando valores crescentes à medida que as amostragens no curso d'água aproximavam-se da foz. Tal fato pode ser atribuído aos diversos lançamentos de efluentes domésticos e agroindustriais, ao longo do rio, que contém grande quantidade de sais, contribuindo para o aumento da condutividade elétrica. Dos efluentes agroindustriais lançados no Rio Santa Maria do Doce, destaca-se a vinhaça, subproduto da fabricação da cachaça, atividade comum na região, especialmente no distrito sede de São Roque do Canaã e em alguns pontos de Santa Teresa. Caracterizada por ser um líquido ácido ( $\mathrm{pH}: 3,5-5,0)$, de odor forte, coloração castanho-escuro e com alto conteúdo orgânico (CHRISTOFOLETTI et al., 2013), a vinhaça torna-se um material altamente poluidor para os corpos hídricos.

Além do lançamento de efluentes, fertilizantes aplicados em culturas agrícolas também podem contribuir para o aumento de sais no rio, quando são carreados via escoamento superficial, fato recorrente na sub-bacia do Santa Maria do Doce. Há de se ponderar, também, que a época em que foi realizada a amostragem coincidiu com um longo período de estiagem na região, fato que pode ter contribuído com o aumento da concentração de sais na água.

Não há um referencial limite quanto aos valores de condutividade elétrica na Resolução do CONAMA n. 357, de 17 de março de 2005 (BRASIL, 2005). No entanto, AYERS \& WESTCOT (1999) afirmam que o grau de restrição do uso da água de irrigação quanto à condutividade elétrica (CEa) é classificada como "nenhuma", quando os valores estiverem abaixo de $0,7 \mathrm{dS} \mathrm{\textrm {m } ^ { - 1 }}\left(700 \mu \mathrm{S} \mathrm{cm}^{-1}\right)$. Dessa forma, ainda que os valores de CE tenham aumentado ao longo do rio até chegar à foz, a qualidade água de todos os pontos amostrados, no que se refere a esse parâmetro, não apresenta restrição de uso para irrigação. No entanto, o monitoramento desse parâmetro torna-se importante uma vez que a utilização de águas salinas na irrigação pode representar risco para produção agrícola de muitas culturas. Com as irrigações, os sais contidos na água acumulam-se na zona radicular, diminuindo a disponibilidade de água.

De acordo com JÚNIOR et al. (2016) os efeitos da salinidade sobre as plantas são decorrentes da redução do potencial osmótico, diminuindo, conseqüentemente, a disponibilidade da água para a planta e pelo efeito iônico, que refere-se aos íons absorvidos pelas plantas, os quais podem provocar desequilíbrio iônico ou toxicidade as mesmas. GARCIA et al. (2008) reforçam que altos níveis de sais nas águas de irrigação, tanto são prejudiciais ao desenvolvimento das culturas como podem causar a obstrução dos sistemas de irrigação.

Em diversos trabalhos de pesquisas é possível verificar o efeito da salinidade no crescimento e desenvolvimento de culturas. NOBRE et al. (2013), ao estudarem o efeito da irrigação com distintos valores de condutividade elétrica - Cea $(0,4$ a 4,4 $\mathrm{dS} \mathrm{m}^{-1}$ ) sobre a germinação da mamoneira cv. BRS Energia observaram que a Porcentagem de Emergência (PE) e o Índice de Velocidade de Emergência (IVE) foram afetadas pela salinidade, com decréscimos respectivos de 3,4 e 3,6\% por aumento unitário da Cea. Em beterraba os níveis de salinidade afetaram significativamente os resultados da produção total e comercial além do diâmetro da raiz, altura e o consumo hídrico das plantas (SILVA et al., 2013). Já GUEDES et al. 
(2015), ao avaliarem diferentes estratégias de uso de água salina na cultura do tomate cereja, cv. 'Carolina', cultivada em ambiente protegido, observaram que o uso de água com salinidade de $3,5 \mathrm{dS} \mathrm{m}^{-1}$ provoca redução significativa em todas as variáveis de crescimento e de produção.

$\mathrm{O} \mathrm{pH}$ representa a concentração de íons hidrogênio $\left(\mathrm{H}^{+}\right)$no meio, indicando sobre a condição de acidez, neutralidade ou alcalinidade da água. De acordo com VON SPERLING (2005), os fatores que determinam o pH da água podem ser de origem natural, através da dissolução de rochas, absorção de gases da atmosfera, oxidação da matéria orgânica e fotossíntese, ou de origem antropogênica, em razão dos despejos domésticos, industriais e agroindustriais. Os valores encontrados para o pH da água variaram de 5,77 a 6,41 (Figura 2b), sendo que o menor e o maior valor, tal como ocorrido para a condutividade elétrica, foram encontrados na nascente e na foz, respectivamente.

Somente os valores de $\mathrm{pH}$ encontrados na nascente e no ponto 2 do Rio Santa Maria do Doce, que compreende o Distrito de Caldeirão pertencente à cidade de Santa Teresa- ES, estão abaixo da faixa aceita pela resolução 357/2005 do CONAMA (BRASIL, 2005), que é de 6,0 a 9,0. No caso do ponto amostrado na nascente, $\mathrm{o} \mathrm{pH}$ ácido pode estar associado à presença de elevada quantidade de sólidos dissolvidos, decorrentes da pecuária extensiva existente próxima ao local. Já no ponto 2, amostrado na região que compreende o Distrito de Caldeirão, o pH baixo da água possa estar associado à oxidação da matéria orgânica, em razão do lançamento de efluentes urbanos e agroindustriais, sem tratamentos no curso d’água.

No que diz respeito ao uso da água para irrigação, VIALLE et al. (2011) afirmam que água com pH inferior a 6,0, apesar de não causar danos às hortaliças e serem tamponadas no solo, são corrosivas, podendo comprometer o sistema de irrigação. No tocante ao risco de entupimento, NAKAYAMA \& BUCKS (1991) classificam em baixo, quando o pH for menor que 7; moderado, quando for entre $7 \mathrm{e}$ 8, e severo, quando for maior que 8. Dessa forma, todos os pontos amostrados ao longo do rio Santa Maria do Doce, apresentam-se com baixo risco de entupimento quanto aos valores de $\mathrm{pH}$.

De acordo com a Figura (2c), os valores de sólidos suspensos variaram de 10 $\mathrm{mg} \mathrm{L}^{-1}$ a $46,67 \mathrm{mg} \mathrm{L}^{-1}$ (Figura 2c), obtidos no ponto oito, que compreende a localidade de Vila Verde, pertencente à cidade de São Roque do Canaã-ES, e no ponto 5, que compreende a localidade de São Sebastião, pertencente à cidade de Santa Teresa-ES, respectivamente. Os maiores valores de sólidos suspensos encontrados neste trabalho possam estar atribuídos à ausência de mata ciliar, às pastagens degradadas e aos topos de morros sem vegetação, verificados na localidade de São Sebastião.

Nessa região, há elevada produção de tomate e café, culturas que envolvem um grande revolvimento de solo no momento do plantio. Além disso, o relevo da área é montanhoso, de modo que os cultivos agrícolas, na maioria das vezes, concentram-se nos morros. Todas essas questões, além da inexistência de práticas conservacionistas, contribuem para o processo de desprendimento e arraste de partículas de solo e material orgânico, contribuindo para o aumento de sólidos em suspensão no leito do rio. Neste sentido, práticas conservacionistas devem ser adotas a fim de minimizar o processo erosivo, e consequentemente o assoreamento e a poluição do manancial. 
A Resolução 357/2005 (BRASIL, 2005) não dispõe de limites críticos de enquadramento de corpos d'água, quanto aos sólidos suspensos. Quanto ao uso da água para irrigação, NAKAYAMA \& BUCKS (1986) classificam em baixo $\left(<50 \mathrm{mg} \mathrm{L}^{-}\right.$ $\left.{ }^{1}\right)$, médio $\left(50-100 \mathrm{mg} \mathrm{L}^{-1}\right)$ e alto $\left(>100 \mathrm{mg} \mathrm{L}^{-1}\right)$ o risco de danos aos sistemas de irrigação. Dessa forma, todos os valores de sólidos suspensos obtidos nos pontos amostrados (Figura 2c) apresentam baixo risco de danos ao sistema de irrigação. No entanto, em estudos experimentais em sistemas de irrigação localizada em que se utilizaram filtros para retenção de partículas foi observado que, para valores de até $20,0 \mathrm{mg} \mathrm{L}^{-1}$ de sólidos suspensos, houve 0 aumento do número de retrolavagem dos filtros devido à perda de carga em função do volume filtrado (RIBEIRO et al., 2005). Dessa forma, evidencia-se a necessidade de se utilizar sistema de filtragem para a água do Rio Santa Maria do Doce.

As concentrações de sólidos suspensos encontrados no decorrer desta pesquisa são menores que às obtidas por DALASTRA et al. (2014) que verificaram valores para sólidos suspensos entre 56 a $208 \mathrm{mg} \mathrm{L}^{-1}$ no córrego do Cedro e por

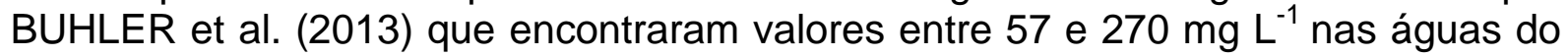
Rio Paraguai no perímetro urbano. Já MOURA et al. (2011) estudando a qualidade da água para uso em irrigação na microbacia do Córrego do Cinturão Verde, Município de llha Solteira obtiveram valores médios parecidos com os deste trabalho, variando entre 15,7 e $22,8 \mathrm{mg} \mathrm{L}^{-1}$.

Os sólidos dissolvidos totais são compostos de todas as substâncias orgânicas e inorgânicas contidas na água. De acordo com a Figura 2d, observa-se que os valores de sólidos dissolvidos totais variaram de 10 a $130 \mathrm{mg} \mathrm{L}^{-1}$, sendo o menor valor encontrado na nascente e o maior na foz. Neste último, tal fato possa estar relacionado ao arraste de partículas orgânicas e inorgânicas pela água da chuva para o leito do rio e pela emissão de dejetos urbanos que por sua vez são conduzidos ao longo do rio até a foz, aumentando a sua concentração.

A resolução do CONAMA $357 / 05$ estabelece o valor máximo de $500 \mathrm{mg} \mathrm{L}^{-1}$ de sólidos dissolvidos para os corpos d'água enquadrados na "Classe 2". Dessa forma, em nenhum dos pontos amostrados este valor foi ultrapassado. Os sólidos dissolvidos totais são um parâmetro muito importante do ponto de vista da irrigação, principalmente na irrigação localizada, como o gotejamento e a microaspersão. Segundo SILVA et al. (2011) concentrações elevadas de partículas sólidas na água obstruem os orifícios distribuidores de água danificando o sistema de irrigação.

No tocante à utilização da água para irrigação, NAKAYAMA \& BUCKS (1986) classificam como baixo risco de entupimento quando a concentração de sólidos dissolvidos for menor que $500 \mathrm{mg} \mathrm{L}^{-1}$; moderado, quando estiver entre 500 e 2000 $\mathrm{mg} \mathrm{L}^{-1}$, e severo, quando for maior que $2000 \mathrm{mg} \mathrm{L}^{-1}$ Dessa forma, todas as amostras analisadas de sólidos dissolvidos totais são classificadas como potencial de baixo risco para o sistema de irrigação.

\section{CONCLUSÃO}

De acordo com os resultados obtidos, pode-se concluir que:

- Em dois pontos amostrados ao longo do Rio Santa Maria do Doce, o pH está abaixo da faixa estabelecida pela resolução CONAMA 357/2005. Em nenhum dos pontos amostrados, o valor de sólidos dissolvidos totais foi ultrapassado, de acordo com o limite da referida resolução.

- Os valores crescentes de condutividade elétrica e sólidos dissolvidos totais no decorrer do leito e principalmente próximo à foz do rio podem estar relacionados 
ao arraste de partículas orgânicas e inorgânicas pela água da chuva e pela emissão de efluentes domésticos e agroindustriais.

- Os maiores valores de sólidos suspensos encontrados neste trabalho possam estar atribuídos à inexistência de práticas conservacionistas na bacia do Rio Santa Maria do Doce.

- Em todos os pontos avaliados ao longo do Rio Santa Maria do Doce, o uso da água para irrigação não apresenta riscos de entupimento, no que se refere aos parâmetros de condutividade elétrica, $\mathrm{pH}$, sólidos suspensos e sólidos dissolvidos.

\section{REFERENCIAS}

AYERS, R. S.; WESTCOT, D. W. A qualidade da água na agricultura. Campina Grande. UFPB. 1991. 218p. Estudos FAO: Irrigação e Drenagem, 29. rev.1.

BUHLER, B. F.; SOUZA, C. A. de; OLIVEIRA JUNIOR, E. S. Qualidade da água do Rio Paraguai no perímetro urbano em Cáceres - MT, BRASIL. Revista GeoPantanal, Corumbá, v. 08, n. 14, 2013. Disponível em: < http://www.seer.ufms.br/index.php/revgeo/article/view/106>.

BRASIL. Ministério do Meio Ambiente. Conselho Nacional do Meio Ambiente (CONAMA). Resolução n. 357, de 17 de março de 2005.

CALVET, A. S. F.; PINTO, C. M.; LIMA, R. E. M.; MAIA-JOCA, R. P. M.; BEZERRA, M. A. Crescimento e acumulação de solutos em feijão-caupi irrigado com águas de salinidade crescente em diferentes fases de desenvolvimento. Revista Irriga, Botucatu, v. 18, n. 01, p. 148-159, 2013. Disponível em: <http://dx.doi.org/10.15809/irriga.2013v18n1p148>.

doi:

10.15809/irriga.2013v18n1p148.

CARVALHO, J. F. de; TSIMPHO, C. J.; SILVA, Ê. F. de F. e; MEDEIROS, P. R. F. de; SANTOS, M. H. V. dos; SANTOS, A. N. dos. Produção e biometria do milho verde irrigado com água salina sob frações de lixiviação. Revista Brasileira de Engenharia Agrícola e Ambiental, v. 16, n. 04, p. 368-374, 2012. Disponível em: < http://dx.doi.org/10.1590/S1415-43662012000400006>. doi: 10.1590/S141543662012000400006.

CHRISTOFOLETTI, C. A.; PEDRO-ESCHER, J; CORREIA, J. E.; MARINHO, J. F. U.; FONTANETTI, C. S. Sugarcane vinasse: Environmental implications of its use. Waste Management, v. 33, p. 2752-2761, 2013. Disponível em: < http://dx.doi.org/10.1016/j.wasman.2013.09.005>.

doi:10.1016/j.wasman.2013.09.005.

DALASTRA, C.; HERNANDEZ, F. B. T.; BARBOZA, G. C.; SONEGO, C. R. Qualidade da água do córrego do Cedro para fins de irrigação na produção de alimentos consumidos in-natura. Revista de Agricultura Neotropical, CassilândiaMS, v. 01, n. 02, p. 52-63, 2014. Disponível em: < http://periodicosonline.uems.br/index.php/agrineo/article/view/242>.

ECOPLAN (2010). Plano Integrado de Recursos Hídricos da Bacia Hidrográfica do Rio Doce e Planos de Ações para as Unidades de Planejamento e Gestão de 
Recursos Hídricos no Âmbito da Bacia do Rio Doce. Disponível em:< http://www.cbhdoce.org.br/wp-content/uploads/2014/10/PARH_SM_Doce.pdf>.

FERREIRA, J. T. P.; FERREIRA, E. P.; OLIVEIRA, M. L.; SILVA, G. S.; FILHO, J. S. O.; SANTOS, J. W. G. Avaliação da fertilidade dos solos cultivados com café Conilon (Coffea canephora) no município de Santa Teresa - ES. Enciclopédia Biosfera, Centro Científico Conhecer - Goiânia, v. 9, n. 16; p. 356-366, 2013.

GARCIA, G. de O.; MARTINS FILHO, S.; REIS, E. F. dos; MORAES, W. B.; NAZÁRIO, A. de A. Alterações químicas de dois solos irrigados com água salina. Revista Ciência Agronômica, v. 39, n. 01, p. 7-18, 2008. Disponível em: <http://www.ccarevista.ufc.br/seer/index.php/ccarevista/article/view/18>.

GUEDES, R. A. A.; OLIVEIRA, F. A.; ALVES, R. C.; MEDEIROS, A. S.; GOMES, L. P.; COSTA, L. P. Estratégias de irrigação com água salina no tomateiro cereja em ambiente protegido. Revista Brasileira de Engenharia Agrícola e Ambiental, Campina Grande, PB. v. 19, n. 10, p. 913-919, 2015. Disponível em:< http://dx.doi.org/10.1590/1807-1929/agriambi.v19n10p913-919>. doi: 10.1590/18071929/agriambi.v19n10p913-919.

JÚNIOR, G. de S. e S.; WILLADINO, L. G.; SILVA, L. E. da; CAMARA, T. R. Efeito da salinidade sobre o desequilíbrio nutricional em genótipos diplóides de bananeira. Revista de Ciência, Tecnologia e Humanidades do IFPE, v. 08, n. 01, p. 20-29, 2016. Disponível em:< http://revistas.ifpe.edu.br/revistas/index.php/cientec/article/view/67>.

LIU, H.; HUANG, G. Laboratory experiment on drip emitter clogging with fresh water and treated sewage effluent. Agricultural Water Management, v. 96, p. 745-756, 2009. Disponível em: <http://dx.doi.org/10.1016/j.agwat.2008.10.014>. doi: 10.1016/j.agwat.2008.10.014.

MATOS, A. T. Qualidade do Meio Físico Ambiental: Práticas de Laboratório. Viçosa: UFV, 2012. 150p.

MOURA, R. da S.; HERNANDEZ, F. B. T.; LEITE, M. A.; FRANCO, R. A. M.; FEITOSA, D. G.; MACHADO, L. F. Qualidade da água para fins de irrigação na Microbacia do Córrego do Cinturão Verde, município de llha Solteira. Revista Brasileira de Agricultura Irrigada, v. 05, n. 01, p. 68-74, 2011. Disponível em:< http://www.inovagri.org.br/revista/index.php/rbai/article/view/62>. doi: 10.7127/RBAI.V5N100014.

NAKAYAMA, F. S.; BUCKS, D. A. Trickle irrigation for crop production. St. Joseph: ASAE, 1986. 383p.

NAKAYAMA, F. S.; BUCKS, D. A. Water quality in drip/trickle irrigation: A review. Irrigation Science, v. 12, p. 187-192, 1991. Disponível em: < http://link.springer.com/article/10.1007/BF00190522>. doi: 10.1007/BF00190522. 
NOBRE, R. G.; LIMA, G. S. de; GHEYI, H. R.; LOURENÇO, G. S.; SOARES, L. A. A. Emergência, crescimento e produção da mamoneira sob estresse salino e adubação nitrogenada. Revista Ciência Agronômica, Fortaleza, v. 44, n. 01, p. 76-85, 2013. Disponível em: <http://dx.doi.org/10.1590/S1806-66902013000100010>. doi: 10.1590/S1806-66902013000100010.

RIBEIRO, T. A. P.; AIROLDI, R. P. da S.; PATERNIANI, J. E. S.; SILVA, M. J. M. da. Variação dos parâmetros físicos, químicos e biológicos da água em um sistema de irrigação localizada. Revista Brasileira de Engenharia Agrícola e Ambiental, v. 09, n. 13, p. 295-301, 2005. Disponível em: <http://dx.doi.org/10.1590/S141543662005000300001 >. doi: 10.1590/S1415-43662005000300001.

RIBEIRO, G. M.; MAIA, C. E.; MEDEIROS, J. F. Uso da regressão linear para estimativa da relação entre a condutividade elétrica e a composição iônica da água de irrigação. Revista Brasileira de Engenharia Agrícola e Ambiental, v. 9, n. 01, p. 15-22, 2005. Disponível em: <http://dx.doi.org/10.1590/S141543662005000100003>. doi: 10.1590/S1415-43662005000100003.

SÁ, F. V. da S.; MESQUITA, E. F. de; BERTINO, A. M. P.; Influencia do gesso e biofertilizante nos atributos químicos de um solo salino-sódico e no crescimento inicial do girassol. Revista Irriga, Botucatu, v. 20, n. 01, p. 46-59, 2015. Disponível em: <http://dx.doi.org/10.15809/irriga.2015v20n1p46>. doi: 10.15809/irriga.2015v20n1p46.

SILVA, I. N.; FONTES, L. O.; TAVELLA, L. B.; OLIVIEIRA, J. B.; OLIVEIRA, A. C. Qualidade de água na Irrigação. Agropecuária Científica no Semi-Árido, v. 07, n. 03, p. $01-05, \quad 2011 . \quad$ Disponível em: < http://revistas.ufcg.edu.br/acsa/index.php/ACSA/article/view/134>.

SILVA, L. P.; SILVA, M. M.; CORREA, M. M.; SOUZA, F. C. D.; SILVA, E. F. F. Desempenho de gotejadores autocompensantes com diferentes efluentes de esgoto doméstico. Revista Brasileira de Engenharia Agrícola e Ambiental, v. 16, n. 05, p. 480-486, 2012. Disponível em: <http://dx.doi.org/10.1590/S141543662012000500003>. doi: 10.1590/S1415-43662012000500003.

SILVA, A. O. da; KLAR, A. E.; SILVA, Ê. F. de F. e. Produção da cultura da beterraba irrigada com água salina. Engenharia na Agricultura, Viçosa, v. 21, n. 03, p. 271-279, 2013. Disponível em: < http://www.seer.ufv.br/seer/index.php/reveng/issue/view/32/showToc>.

VIALLE, C.; SABLAYROLLES, C.; LOVERA, M.; JACOB, S.; HUAU, M. C.; MONTREJAUDVIGNOLES, $M$. Monitoring of water quality from roof runoff: interpretation using multivariate analysis. Water Research, v. 45 , n. 12, p. 37653775, 2011. Disponível em: < http://www.ncbi.nlm.nih.gov/pubmed/21561638>. doi: 10.1016 / j.watres.2011.04.029.

VON SPERLING, M. Introdução à qualidade das águas e ao tratamento de esgotos. -3 ed. - Belo Horizonte: Departamento de Engenharia Sanitária e Ambiental- Universidade Federal de Minas Gerais. 2005. 